ONLINE LEARNING THROUGH THE STAR LIBRARY NETWORK: RESOURCES, NETWORKING, AND APPLIED PRACTICE IN STEM PROGRAM FACILITATION

Keliann LaConte, 1, ${ }^{*}$ Brooks Mitchell,1 Ginger Fitzhugh,2 \& Carrie Liston2

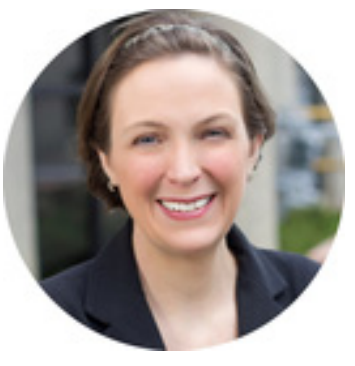

Keliann LaConte

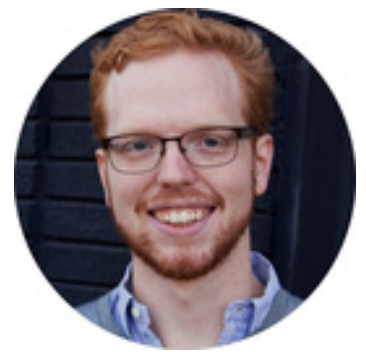

Brooks Mitchell

1 Space Science Institute, 4750 Walnut Street, Suite 205, Boulder, Colorado 80301-2532, USA

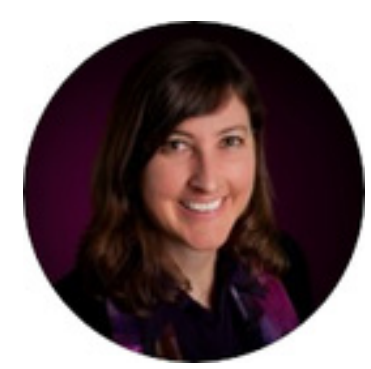

Ginger Fitzhugh

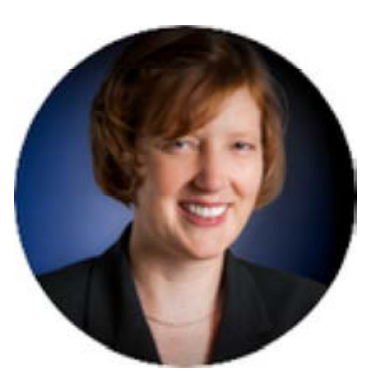

Carrie Liston

2 Education Development Center, 43 Foundry Avenue, Waltham, Massachusetts 02453, USA

${ }^{*}$ Address all correspondence to: Keliann LaConte, Space Science Institute, 4750 Walnut Street, Suite 205, Boulder, CO 80301-2532, USA; Tel.: (+1) 720-974-5835, E-mail: klaconte@spacescience.org

\title{
Abstract
}

The STAR Library Network (STAR Net) utilizes webinars as a key tool in its suite of professional learning opportunities relating to STEM learning in libraries. Traditionally, continuing education for library staff has taken place in person, such as at conferences and workshops. While these touch points provide crucial face-to-face networking opportunities, highly interactive webinars provide learning conversations that help bridge the gap between frameworks and resources to practical application in daily practice. 
Through webinars, STAR Net shares ideas, demonstrates activities, and engages with library staff from anywhere in the country, and the free access to webinar recordings allows staff members to view them when most convenient. When used in conjunction with broader professional learning opportunities, webinars can have a major impact on library staff in adopting successful STEM facilitation strategies for their library programs and services. Key STEM programming opportunities, including the 2017 solar eclipse and NASA@ My Library events, have given library staff a focal point for participating in ongoing online training.

KEY WORDS: webinar, STEM, practical, community of practice, interactive, continuing education, hands-on, program development

\section{STEM IN LIBRARIES}

Libraries build on a deep history of promoting knowledge and learning, reaching four millennia into our past. They developed expertise in materials that could be circulated, with the community accessing the library to consume media and services (Lankes, 2015). As they continue to evolve to meet the demands of the digital age (Pew Research Center, 2013), library staff now help patrons use interactive websites on specific subjects, learn how to use myriad online tools, and circulate much more than books (Lankes, 2015). Science, technology, engineering, or mathematics-related skills and concepts_popularized in education parlance as "STEM"-are increasingly offered as part of library programs and services. Baek (2013) examined the impact of STEM programming on library staff using the concept of an accidental STEM librarian (i.e., a librarian who does not have professional training in STEM programming). Library staff have asked for, and need, more training in STEM facilitation (Hakala et al., 2016; MacCarthy, 2015).

The STAR Library Network (STAR Net) is a hands-on learning network for libraries and their communities across the country (www.starnetlibraries.org). STAR Net focuses on helping library professionals build their STEM skills by providing "science-technology activities and resources" (STAR) and training to use those resources. It includes the STAR Net webinar series, the STEM Activity Clearinghouse, blogs, in-person training events, and a bimonthly e-newsletter. Through several STAR Net initiatives, traveling exhibits or STEM kits were provided as physical resources to participating libraries. Partners include the American Library Association, Afterschool Alliance, Collaborative Summer Library Program, Cornerstones of Science, Lunar and Planetary Institute, University of Virginia, and many others.

Many libraries already offer opportunities for active, hands-on, engaged learning-programs that allow youth to be active producers of content rather than just 
consumers of materials-making them an ideal environment for STEM learning (e.g., Ito et al., 2010; Glass, 2015; Moorefield-Lang, 2015). They are also being called upon to "facilitate the use and sharing of STEM expertise already existent in the community by the community" (Lankes, 2015). Results from a recent national STAR Net survey suggest that STEM programming is offered fairly frequently in public libraries: $30 \%$ offer STEM programming at least "occasionally" (2 or more times a year), 29\% offer STEM programming "frequently" (more than once per month), and 26\% offer STEM programming "monthly" ( $n=455)$. Only $15 \%$ of libraries responded that they only offered STEM programming in the summer or had "tried it once." Nearly 500 public library staff participated in the survey; $36 \%$ of respondents identified their communities as rural, $18 \%$ as suburban/rural, and $17 \%$ as city/suburb, with smaller percentages identifying as city $(11 \%)$, suburban $(15 \%)$, or "other" $(4 \%)$ types of communities $(n=499)$. Interviews were also conducted with 23 librarians who responded to the survey; these open-ended conversations provided context and additional details for the survey results (Hakala et al., 2016).

\section{ADDRESSING NEEDS THROUGH AN ONLINE COMMUNITY OF PRACTICE}

Lack of staff time and funds are the top-cited barriers to offering STEM programs (Hakala et al., 2016; LaConte et al., 2014). Lack of materials and space are also of concern. "Library staff not prepared to lead STEM-based activities, demos, or discussions" (42\%) and "Library staff not knowledgeable about STEM topics" (38\%) were the fifth and sixth most-cited barriers, respectively, in the 2015 STAR Net survey. STAR Net addresses these needs through a combination of an online community of practice and professional learning opportunities.

The STAR Net community of practice engages 7000 staff from public libraries and bookmobiles, state libraries, and library associations, as well as representatives from STEM educational organizations. Members access the public website, which consists of resources, hands-on activities (described below), and media. Registered members also receive the electronic STAR Net News, which highlights relevant hands-on STEM activities, upcoming and archived webinars, and programming opportunities twice a month. Public library staff post blogs detailing STEM programs and valuable resources, and their blogs have been accessed about 19,000 times. State libraries and library associations are critical members of this thriving network, as they promote opportunities, such as webinars, and connect STAR Net to cutting-edge trends within the library profession. Library and Information Science faculty have advised the development of STAR Net focus areas (e.g., Lankes, 2015; LaConte et al., 2018). 
There is a plethora of online STEM educational resources available for library staff from reliable sources, including multimedia assets, databases of potential partners, and programming ideas. Availability, however, does not always mean accessibility. Many library staff are not aware of these free resources. Others may struggle with navigating through the sheer volume of resources and filtering out what is useful and reliable. Even more challenging, many resources are developed for classrooms or structured afterschool programs and do not readily transfer to the free-choice library learning environment. Libraries are a unique learning environment with facilitators and learners of many different levels. Therefore, learning resources must ultimately be seen as accessible, valuable, and useful for serving library patrons.

The STEM Activity Clearinghouse is a one-stop shop for free STEM activities for use in the library setting. Its holdings currently number over 200 activities, including those produced through the STAR Net project and from reliable sources across the internet, such as NASA, PBS, and the American Society of Civil Engineers. Each activity is accompanied by tips on use in the library setting, links to related content and online video clips, and suggested books. Where possible, how-to videos are provided with the activities. Facilitators can search the Clearinghouse based on cost, ages served, content area, level of STEM proficiency required, and other parameters. The Clearinghouse also includes an "Add a Tech Twist" notation, which offers recommendations on ways that high-tech STEM tools (such as a digital microscope or infrared thermometer) can be integrated into handson activities. Library staff are being actively engaged to build up the Clearinghouse review system with front-line perceptions of the various resources. This process actively engages STAR Net members as participants in a community of practice, supporting their ongoing implementation of STEM in libraries.

\section{ADDRESSING NEEDS THROUGH INTERACTIVE WEBINARS}

The STAR Library Network utilizes webinars as a key tool in its suite of professional learning opportunities. The STAR Net webinar series serves two main purposes: (1) providing an opportunity for library staff to receive information and interact with STEM resource providers and (2) providing interactive training with a focus on hands-on activities. Through webinars, STAR Net shares ideas, demonstrates activities, and engages with library staff from anywhere in the country, and the free access to webinar recordings allows library staff to view them when most convenient. Webinars are offered monthly to bimonthly, and public library staff nationwide are encouraged to register (for free) to receive reminders and follow-up communications. From the outset of each webinar, attendees are engaged with poll questions and asked to introduce themselves, and STAR Net webinar attendees are typically highly active in the webinar platform's chat feature. Attendees are encouraged to interact with each other by sharing resources, 
suggesting adaptations to the showcased activity, or expressing challenges that they face. Multiple presenters are involved in facilitating webinars, each with a roll to engage with the audience through polls, video feeds of presenters and demonstrations, and chat. To support ongoing connections to practice, attendees are encouraged to submit reviews of activities they implement to the Clearinghouse. Webinar recordings are readily available on the STAR Net website and YouTube and allow library staff to review material multiple times. From July 2017 to July 2018, STAR Net webinar recordings were viewed more than 2000 times.

Highly interactive in-person training for library staff in STEM topics has proven effective, and those successes inform the design of the STAR Net webinar series. Evaluation of the Lunar and Planetary Institute's workshop training model demonstrate the success of interactive, in-person professional development. Workshops were two days in length and focused on a selection of 7-12 hands-on STEM activities. As they went through each of the activities, workshop facilitators led participants in discussions about how to adapt the activities for their own programming needs and pointed out strategies for engaging learners in STEM explorations. Participating library staff were "less than comfortable with STEM content" prior to a workshop, but very comfortable afterward ( $n=70$, Peters, 2006). Participants reported increased preparedness, confidence, and perceived ability to lead space science activities as a result of a workshop (Swackhamer and Holdgreve-Resendez, 2013). A follow-up study of workshop participants demonstrated that respondents were over $75 \%$ more likely to advocate for including science and engineering in their programming as a result of training ( $n=168$, LaConte et al., 2014). In-person training opportunities are described by library staff as "key to get buy-in" into taking on STEM facilitation roles (Holland, 2016). While beneficial for those who can attend, this model of professional development leaves behind those that cannot, including geographically isolated libraries and underfunded libraries.

The STAR Net webinar series addresses these issues by highlighting resources and tools and partnering with guest speakers from vetted sources, including organizations such as NASA, the American Society of Civil Engineering, and the Public Library Association. These webinars support library program design and promotion with resources relating to STEM content (e.g., "STEM Events for Your Library's 2018 Programming"), community connections (e.g., "Reaching New Audiences with Community Dialogues"), and program promotion (e.g., "Social Media Tips from NASA"). STEM organizations and networks also highlight opportunities to connect with local subject matter experts (e.g., "NASA Partnerships in Your Own Backyard"). Online resources are suggested in chat throughout the presentation as a way to "walk" participants through the most relevant (vetted) resources on the internet. Guest speakers present their resources on the STAR Net blog 
to provide "evergreen" access to websites and other resources, and registered members of the STAR Net community post comments in response to blog articles.

As the STEM professions continue to produce new discoveries, tools, and approaches, webinars offer library staff a way to introduce these frontiers to their patrons. Hands-on activity demonstrations provide an interactive way to visualize and explore those STEM frontiers in ways that can immediately be integrated into library programs. One- to twohour interactive webinars that focus on the facilitation of hands-on STEM activities are a key component of the STAR Net webinar series. These webinars typically highlight activities from the STEM Activity Clearinghouse. Participants in the NASA@ My Library initiative have participated in additional training to prepare them to use STEM facilitation kits competitively awarded to select libraries. Participants are encouraged to have the materials for the STEM activity on hand to undertake the activity for themselves as it is demonstrated online. This in-depth, interactive format provides informational context about the activities and models and their effective facilitation tactics. These webinars may focus on a specific theme (e.g., "Building a Better Program for Engineer's Week") or highlight the newest additions to the STEM Activity Clearinghouse (e.g., "Hands-On Fun with STAR Net!"). If facilitating an engineering design challenge, for example, the webinar presenters may ask the attendees for suggestions on how they can improve their design before testing again. Such two-way exchanges can inform the facilitator on the participants' prior knowledge and allow him or her to check for current understanding. By introducing new activity ideas, STEM concepts, and facilitation styles, these webinars prepare library staff to develop and implement STEM programs at their institution.

STAR Net places an emphasis on conducting webinars in conjunction with important STEM events and initiatives, including NASA mission launches, national science celebrations, and library advocacy programs. These webinars typically feature a subject matter expert guest speaker, highlight available resources and opportunities related to the event or initiative, and demonstrate a hands-on activity facilitation. After attending a onehour STAR Net webinar on a specific STEM event, library staff are more knowledgeable on a specific subject, which gives them confidence in facilitating STEM programming. In addition, they have new resources, tools, and activity ideas for developing STEM-based programming.

The 2017 total solar eclipse provided a unique opportunity for STAR Net to leverage its reach within the library community to provide scientific, cultural, safety, and programming information to thousands of library staff across the country. The STAR Net webinar series played a crucial role in these efforts. From June 2016 to August 2017, the STAR Net team presented eight eclipse-related webinars. Highlights include "Safe Eclipse Viewing" with Dr. Doug Duncan of the Fiske Planetarium, "Eclipse Cultural Connections" with Dr. 
Isabelle Hawkins of the Exploratorium, "Total Eclipse 2017: The Outreach Event of the Decade" with Dr. Andrew Fraknoi and Dr. Dennis Schatz, and "Crowd-Pleasing Hands-On Activities for Your Eclipse Programs." In 2017 alone, eclipse-related STAR Net webinars were viewed more than 1200 times. These webinars served a very important role in providing valuable safety information and STEM activities to library staff across the country as they prepared for the national event.

\section{WEBINAR EVALUATION RESULTS}

Three of these STAR Net webinars were offered in spring 2013, reaching a total of 282 participants. Surveys were administered immediately after each webinar and 35\% of attendees $(n=99)$ responded. Webinar participants reported gains in their knowledge about how to facilitate hands-on STEM activities, as well as in their confidence and their interest in doing so at their public library. At least nine out of ten survey respondents said they planned to implement what they learned in the webinar. Attendees said the webinars were engaging, practical, and inspiring. One library staff member commented:

"I think the webinar was great. I was initially a little worried about the length of it, but I found myself interested and attentive through the entire program. I liked the way that you all made it interactive for the audience. That is something that I haven't seen in a lot of the webinars I have attended. Very nicely done. I also really liked the use of the video. It's nice to have a face to go along with the speaker. It is one of the best webinars that I have been to."

Attendees commented that it was not only helpful to watch presenters demonstrate activities, but that completing the activities alongside the presenters gave them confidence that they could easily implement the activities at their library. For example, one library professional commented that "seeing how fun and simple some of these activities can be makes me realize we can do this," while another noted, "The webinar reinspired me to plan more science programs." Many attendees said they appreciated that the webinars provided opportunities for attendees to contribute to the conversation (via the chat function) and thereby learn from others who had facilitated those or similar activities. Some attendees said the webinars helped them feel like part of a larger community. As one person put it, "we're all in this together."

Using technology to share information in real time is not without challenges. While uncommon, a few libraries with limited internet bandwidth reported difficulty streaming the webinars. The STAR Net team also learned it is important to conduct sound level checks prior to the start of each webinar to ensure that presenters in different locations were adequately connected via microphone and that their sound levels were similar. Online meeting software makes it possible to share a wealth of information simultaneously 
through multiple presentations modes. Some webinar attendees said they found it overwhelming to try to attend to the slides, the presenters' audio/video, and the chat function simultaneously. Participants said they appreciated that the webinars were recorded so that they could watch them again later to pay attention to the parts they missed.

\section{DISCUSSION}

Taken together, STAR Net offers multiple points for library professionals to be introduced to-or expand-their continuing education in STEM, including the STAR Net webinar series, the STEM Activity Clearinghouse, blogs, in-person training events, and a monthly e-newsletter. Webinars will never completely replace the impact that an in-person workshop can have on library staff in terms of trying new hands-on activities or networking with like-minded professionals. However, the online learning environment sustains STAR Net's national community of STEM programming library staff with ongoing access to information, resources, and examples of STEM learning in libraries. The Clearinghouse and blog are critically tied to practice and offer on-the-ground perspectives for the benefit of the entire community. In the case of the 2017 total solar eclipse, the broad reach of the STAR Net webinar series was instrumental in empowering libraries to do what they do best: being beacons of safe, vetted information, resources, and programs for their communities.

In follow-up surveys, library professionals have reported that webinars are an effective and efficient means for learning, especially in combination with other types of professional development and supports (including in-person learning, online community of practice, and resources). Although a small number of library staff reported feeling overwhelmed by the amount of resources, many said they appreciated having a variety of supports available that use different modes of delivery. For example, one library professional participating in NASA@ My Library said, "I believe the open discussions, informal web meetings, sharing of resource options, and quick responses received so far by staff have made me feel prepared to facilitate [STEM] programming." On a survey administered to library staff from the 75 libraries participating in the NASA@ My Library following, respondents were asked to indicate the degree to which they thought various types of support (including STAR Net webinars, the NASA@ My Library online community of practice, and an in-person workshop) had been or would help them implement STEM programming at their library. While library professionals anticipated that the upcoming in-person workshop would be the most helpful to them, online webinars came in a close second. About three quarters of the respondents said the webinars were "very" or "moderately" helpful (76\%, including $47 \%$ who said webinars were "very" helpful; $n=231$ ), only slightly less than the percentage of respondents who said they anticipated the in-person workshop would be helpful to them 
(78\%, including 59\% who said "very" helpful, $n=227$ ). For many library professionals, online professional development is a desirable learning option.

STAR Net positions itself as both a stand-alone tool for library staff without access to inperson training as well as a supplemental resource to more comprehensive professional development efforts. A STAR Net in-person workshop, for example, may focus more on specific facilitation skills (e.g., verbal cues for interacting with patrons, modeling "Guide on the Side" behavior) and networking with other STEM practitioners to discuss best practices (e.g., Fitzhugh et al., 2013). Online resources, such as webinars, newsletters, community dialogue guides, media templates, etc., are introduced as a way for attendees to stay connected to the network.

In the case of the 2017 total solar eclipse, the STAR Library Network leveraged its wide reach to deliver important safety information to thousands of library staff, who in turn shared that with the general public. Informational webinars began over a year in advance, and online resources were developed and released to the public as buildup to the event began. Library staff turned to STAR Net-a liaison between the library profession and the STEM education community —as a vetted source of information and resources.

\section{RECOMMENDATIONS AND CONCLUSION}

As the field of librarianship continues to evolve to meet the needs of the digital age, the STAR Library Network provides critical access to continuing education in programming and partnership, as well as practical guidance relating to STEM. In-person professional learning experiences at conferences and workshops continue to be an essential part of comprehensive continuing education, particularly when those experiences are hands-on or otherwise active in nature. Highly interactive webinars can provide crucial learning conversations that help bridge the gap between frameworks and resources to practical application in daily practice.

Future education efforts for library staff will find success in leveraging the strengths of the online learning environment: chat interactivity that invites synchronous exchange of ideas and perspectives, polls that inform the facilitator on the participants' prior knowledge and current understanding, video feeds of presenters and demonstrations, links to related internet resources, and archived recordings for later review. Webinars are especially effective when participants join the experience with common goals and can immediately apply their learning to practice, such as preparing for a national event like the 2017 solar eclipse or preparing to use a common set of materials in their upcoming STEM programs. Universities, science centers and museums, zoos and aquariums, and community organizations like 4- $\mathrm{H}$ have all been active partners and collaborators with libraries on STEM programs (Hakala et al., 2016). In addition to supporting STEM programs at partner 
libraries, these institutions and organizations can help library staff address key needs in evaluation and increasing diversity and inclusion efforts. Library staff have indicated an interest in evaluating the impact of their programs on patrons and/or collecting patron satisfaction feedback. Library staff will need to have access to more ready-made or easily adaptable evaluation tools. Furthermore, the fields of STEM education and librarianship share a dedication to providing lifelong learning opportunities for diverse audiences, and future collaborations should leverage this common interest. STAR Net maintains a selection of strategic planning resources, such as key reports, examples of evaluation efforts around STEM learning in libraries, and recommendations for furthering STEM equity goals. These are available at http://www.starnetlibraries.org/stem-in-libraries.

\section{ACKNOWLEDGMENTS}

The authors would like to thank the members of the STAR Library Network and its NASA@ My Library initiative for continuing to share the results of their ongoing "experiments" with STEM programming in their libraries, as well as their continued participation in STAR Net learning opportunities and its evaluation efforts. The authors would also like to thank the rest of the Education Development Center Inc. (EDC) evaluation team for their contributions to data collection and analysis, including Sarah Armstrong, Vicky Coulon, Jennifer Jocz, and Tracy McMahon. Thanks also to Julie Elworth for her contributions to the evaluation. NASA@ My Library is based upon work funded by NASA under Cooperative Agreement No. NNX16AE30A. Any opinions, findings, and conclusions or recommendations expressed in this material are those of NASA@ My Library and do not necessarily reflect the views of the National Aeronautics and Space Administration. This material is based upon work supported by the National Science Foundation under Grants No. DRL-1657593 and No. DRL-1421427. Any opinions, findings, and conclusions or recommendations expressed in this material are those of the authors and do not necessarily reflect the views of the National Science Foundation. The eclipse project was supported by the Gordon and Betty Moore Foundation through Grant No. 5373. The STEM Activity Clearinghouse was established through partnerships and funding from the Institute of Museum and Library Services (Grant No. LG-80-15-0041-15).

\section{REFERENCES}

Baek, J. (2013), The Accidental STEM Librarian: An Exploratory Interview Study with Eight Librarians, retrieved May 31, 2016, from http://ncil.spacescience.org.

Fitzhugh, G., Coulon, V., and Elworth, J. (2013), STAR Net Summative Evaluation Report, retrieved Oct 20, 2016, from http://ncil.spacescience.org.

Glass, M. (2015), Learning Labs in Libraries and Museums: Case Studies in Collaboration, retrieved July 14, 2015, from www.stemlibraryconference.org. 
Hakala, J.S., MacCarthy, K., Dewaele, C., Wells, M., Dusenbery, P., and LaConte, K. (2016), STEM in Public Libraries: National Survey Results, retrieved July 21, 2017, from http://ncil.spacescience.org.

Holland, A. (2016), STEM Clearinghouse Focus Group Report, retrieved July 14, 2017, from http://ncil.spacescience.org.

Ito, M., Baumer, S., Bittanti, M., Boyd, D., Cody, R., Herr-Stephenson, B., Horst, H.A., Lange, P.G, Mahendran, D., Martinez, K.Z., Pascoe, C., Perkel, D., Robinson, L., Sims, C., and Tripp, L. (2010), Hanging Out, Messing Around, and Geeking Out: Kids Living and Learning with New Media, Cambridge, MA: MIT Press.

LaConte, K.M.G., Lankes, R.D., Stansbury, M., and Subramaniam, M. (2018), STEM in Libraries: Opportunities and Alliances for LIS Educators in This Uncharted Territory, Association for Library and Information Science Education Annual Conference, Proc. of the Association for Library and Information Science Education Annu. Conf., Denver, CO, p. 244.

LaConte, K., Shipp, S., Shupla, C., Shaner, A., Buxner, S., Canipe, M., and Jaksha, A. (2014), Tested Tools and Techniques for Promoting STEM Programming in Libraries, Celebrating Science: Putting Education Best Practices to Work, Astronomical Society of the Pacific Conference Series, vol. 500, pp. 27-35.

Lankes, D.R. (2015), Expect More: Why Libraries Cannot Become STEM Educators, retrieved July 14, 2015, from www.stemlibraryconference.org.

MacCarthy, K. (2015), 2015 Public Libraries \& STEM Conference Evaluation: Final Report, retrieved August 25, 2016, from http://ncil.spacescience.org.

Moorefield-Lang, H.M. (2015), Change in the Making: Makerspaces and the EverChanging Landscape of Libraries, TechTrends, vol. 59, no. 3, pp. 107-112.

Peters, E.E. (2006), To the Moon and Beyond: Engaging Children in Current NASA Lunar Exploration in the Library Environment, retrieved Sept 27, 2016, from https://smdepo.org/ post/1761.

Pew Research Center (2013), Library Services in the Digital Age, retrieved Oct 22, 2016, from http://www.pewinternet.org/2013/01/22/library-services/.

Swackhamer, L.E. and Holdgreve-Resendez, R. (2013), Juno Education and Outreach Program - LPI Explore!, retrieved Dec 10, 2014, from https://www.Ipi.usra.edu/ education/evaluation. 